\title{
MAATSKAPLIKE WERKERS BY WELSYNSINSTANSIES SE BENUT- TING VAN KOMMUNIKASIEMEDIUMS EN -HULPMIDDELS
}

\section{Raelene Arendse}

\section{INLEIDING}

Diensleweringsprogramme van welsynsinstansies fokus op die persoonlike sowel as die sosiale ontwikkeling van individue, gesinne en gemeenskappe. Die ontwikkeling word bevorder deur direkte dienste soos opvoeding, opleiding, terapie en beraad (Lewis, Lewis, Packard \& Souflee, 2001:6). Hierdie direkte dienslewering word uitgevoer deur middel van gevalle-, groep- en gemeenskapswerk. Vir suksesvolle dienslewering aan die verbruikersisteem is dit nodig dat vakkundige personeel in ' $n$ welsynsinstansie kommunikeer oor hoe diensleweringsprogramme kan fokus om hierdie ontwikkeling van individue, groepe en gemeenskappe te bevorder. Dit is daarom noodsaaklik dat daar binne die organisasiestruktuur 'n effektiewe kommunikasiesisteem tussen personeel op verskillende hiërargiese vlakke behoort te bestaan.

Skidmore (1995:197) meen dat kommunikasie die kern van alle menslike verhoudings is en dit vorm ' $n$ integrale deel van werksverhoudings binne 'n welsynsinstansie. Kommunikasie tussen personeel op verskillende vlakke in 'n welsynsinstansie speel 'n belangrike rol in die effektiewe dienslewering aan die verbruikersisteem. Kadushin en Harkness (2002:64) is van mening dat daar ' $n$ formele kanaal van kommunikasie in ' $n$ welsynsinstansie behoort te bestaan wat die aard van die werk en die uitvoering daarvan aan individuele maatskaplike werkers verduidelik.

'n Goed ontwikkelde kommunikasiestruktuur in 'n welsynsinstansie behoort te bestaan ten einde kwaliteitdiens aan die verbruikersisteem te lewer. Die effektiewe benutting van kommunikasiemediums en -hulpmiddels deur maatskaplike werkers kan bydra tot hierdie kwaliteit -dienslewering. Die doel van die navorsing is om te bepaal hoe geslaagd die benutting van kommunikasiemediums en -hulpmiddels vir die verspreiding van inligting aan personeel in 'n welsynsinstansie is, om kwaliteit-dienslewering aan verbruikers te bevorder.

\section{METODE VAN ONDERSOEK}

'n Kwantitatiewe, verkennende ondersoek is onderneem. Tien maatskaplike werkers van een privaat-welsynsinstansie in die Kaapse Metropool is by die studie ingesluit. Die betrokke welsynsinstansie is 'n gesinsorgorganisasie wat dienste aan 'n diverse kliëntsisteem in verskillende geografiese gemeenskappe in die Kaapse Metropool lewer. Die maatskaplike werkers is deur doelbewuste seleksie by die studie betrek. De Vos, Strydom, Fouché en Delport (2002:202) en Babbie en Mouton (2001:166) is dit eens dat doelbewuste seleksie by die oordeel van die navorser berus asook om by die doel van die studie aan te pas. Vraelyste is as datainsamelingsinstrument gebruik. $\mathrm{Na}$ die data-analise is die bevindinge aan die hand van relevante vakliteratuur ontleed en interpreteer.

\section{DEFINISIES VAN KOMMUNIKASIE}

Verskillende definisies van organisatoriese kommunikasie dien as teoretiese vertrekpunt vir die studie. Tubbs en Moss (1994:6) definieer kommunikasie as volg: “...is the process of creating meaning between two or more people." Uit die definisie blyk dit dat kommunikasie tussen twee of meer persone plaasvind en dat dit daarop gerig is om betekenis aan dit wat gekommunikeer word, te gee. In die welsynsinstansie is dit die doel om oor diensleweringsaspekte te 
kommunikeer. Kelly (2000:92-101) definieer organisatoriese kommunikasie as: "...the process by which information is exchanged and understood by two or more people, usually with the intent to motivate or influence behavior". In hierdie kommunikasie kommunikeer personeel primêr oor diensleweringsprogramme, beleid en werkswyses ten einde 'n effektiewe diens aan die verbruikersisteem te lewer. Verder vind kommunikasie tussen bestuur en personeel, personeel onderling en tussen eksterne sisteme plaas om organisasiedoelstellings te bereik, en om kwaliteit-dienslewering aan die verbruikersisteem te bevorder.

\section{DIE DOEL VAN KOMMUNIKASIE IN'N WELSYNSINSTANSIE}

Kommunikasie word as die kern van 'n goed ontwikkelde administrasieproses in 'n welsynsinstansie beskou. Indien werkers die doel van kommunikasie in 'n welsynsinstansie begryp, kan hul individuele bydraes kwaliteit-dienslewering aan die verbruikersisteem verseker. Skidmore (1995:197) identifiseer drie redes waarom kommunikasie in die administrasieproses belangrik is, naamlik om die effektiwiteit en doeltreffendheid van dienslewering te bevorder en om die moraal van werkers te verhoog. Die drie aspekte word vervolgens bespreek.

\section{Effektiwiteit van dienslewering}

Skidmore (1995:198) konstateer dat hierdie effektiwiteit van dienslewering in 'n welsynsinstansie verband hou daarmee dat personeellede met mekaar oor die uitvoering of formulering van beleidsriglyne kan kommunikeer. 'n Voorbeeld hiervan is as maatskaplike werkers kommunikeer oor ' $\mathrm{n}$ beleidsdokument soos die Witskrif vir Welsyn oor dienslewering aan verskillende teikengroepe in 'n welsynsinstansie se diensleweringsgebied. Gebrekkige kommunikasie in die werkplek oor beleid, prosedures en werkswyses kan daartoe aanleiding gee dat motiveringsvlakke van maatskaplike werkers laag is, wat dan taakuitvoering kan strem. Daar moet duidelike riglyne vir maatskaplike werkers bestaan oor hoe taakuitvoering moet geskied in terme van beleid, prosedures en werkswyses van die welsynsinstansie. Dit sal vervolgens kan bydra tot kwaliteit-dienslewering aan die verbruikersisteem.

In die welsynsinstansie is dit die bestuurder se taak om met personeel te kommunikeer oor beleid, prosedures en werkswyses oor dienslewering en algemene personeelaangeleenthede. Dit word ondersteun deur Smit en Cronjé (2002:76) wat die opinie huldig dat die meerderheid van 'n bestuurder se tyd aan kommunikasie bestee word en dat al die voorgenoemde aspekte deel uitmaak van hierdie bestuurstaak. Gebrekkige kommunikasie oor byvoorbeeld welsynsbeleid kan daartoe lei dat beleidsriglyne nie nagekom en nie aangepas kan word nie indien daar leemtes in die diensleweringsisteem sou bestaan nie. Dit kan 'n negatiewe impak op die kwaliteit van dienslewering aan die verbruikersisteem hê. Cooper Altman (2003:474) neem hierdie bespreking verder en beskou twee-rigtingkommunikasie tussen bestuur en personeel as belangrik, want hiersonder kan werkswyses nie aangepas word nie. Beide die bestuur en individuele maatskaplike werkers behoort betrokke te wees by beleidsverandering- of besluitnemingsprosesse in 'n welsynsinstansie om kwaliteit-dienslewering aan die verbruikersisteem te bevorder.

\section{Doeltreffendheid van dienslewering}

Doeltreffendheid van dienslewering word bevorder as personeellede in die welsynsinstansie oor spesifieke prosedures, metodes, kliëntsisteme, beleid en doelstellings kommunikeer. Volgens Neuman (2003:7) is dit noodsaaklik dat daar 'n oop kommunikasiesisteem in die welsynsinstansie moet bestaan, want dit lei tot gehalteversekering. Prosesse sowel as metodes kan deurlopend geëvalueer en aangepas word sodat dit by die organisasieklimaat kan aanpas. 
Schultz (2003:118) sluit hierby aan en beskou kommunikasie as 'n meganisme waar personeel aksies kan koördineer en inligting kan deel wat tot effektiewe organisasie funksionering bydra. As 'n maatskaplike werker deur middel van dienslewering of navorsing 'n spesifieke metode of tegniek ontdek wat dienslewering kan verbeter, behoort dit met kollegas gedeel te word. 'n Voorbeeld hiervan is wanneer 'n maatskaplike werker se gevallelading uit tien pleegsorggevalle met adolessente kinders bestaan en die werker bepaal na assessering dat daar 'n gemeenskaplike probleem is, naamlik onbeheerbare adolessente met gedragsprobleme. Die werker sal dan na afloop van die assesseringsproses kan besluit om eerder die tien adolessente by groepwerk te betrek omdat daar 'n gemeenskaplike probleem is, naamlik onbeheerbare adolessente met gedragsprobleme en dat hierdie probleem meer effektief binne groepsverband hanteer kan word, eerder as om die adolessente by gevallewerk te betrek. Die veranderde intervensiemetode lei tot koste-doeltreffende dienslewering wat duplisering van dienste verhoed en tyd van die maatskaplike werkers in die welsynsinstansie bespaar. Dit is noodsaaklik dat die geslaagde werkswyse van een individuele maatskaplike werker met ander maatskaplike werkers in die welsynsinstansie gedeel word. Indien ander maatskaplike werkers dieselfde metode in diensleweringspraktyke sou kon gebruik, kan dit tot voordeel van die welsynsinstansie wees. Dit bevorder kwaliteit-dienslewering aan die verbruikersisteem en lei terselfdertyd tot koste-doeltreffende dienslewering.

\section{Moraal van werkers}

Die handhawing van 'n hoë moraal van maatskaplike werkers in 'n welsynsinstansie is noodsaaklik vir effektiewe dienslewering aan die verbruikersisteem. Indien bestuurders en maatskaplike werkers in ' $n$ instansie kan saamwerk, verhoog dit die motivering van werkers en lei dit tot doelbereiking. Werner (2003:37) beklemtoon dat mense uniek is en dat elke individu 'n waardevolle bydrae in organisasieverband kan maak, byvoorbeeld oor beleid, werkswyses en metodes van dienslewering. Die maatskaplike werkers se individuele bydraes moet egter tot lae moraal en gebrekkige motivering by werkers lei. Die bestuur en maatskaplike werkers moet oor aspekte wat dienslewering strem of bevorder, kan kommunikeer. Volgens Packard (2001:40) is dit nodig dat die bestuurder in ' $n$ instansie duidelike rigting en leiding oor verwagtinge oor werksfunksionering moet verskaf om maatskaplike werkers se motivering te verhoog. Dit sal tot organisatoriese doelbereiking bydra. Indien 'n bestuurder in 'n welsynsinstansie outokraties is en geen deelnemende bestuur aanmoedig nie, kan dit lei tot gebrekkige motivering en lae moraal by ondergeskiktes, sowel as 'n afname in produktiwiteit. Individuele maatskaplike werkers sou ongemotiveerd kan wees om idees en besluite voor te lê as dit nie erken sou word nie. Dit kan hulle moraal beïnvloed, wat dan weer dienslewering aan die verbruikersisteem kan strem. Voorts voer Giffords en Dina (2003:77) aan dat dit belangrik is vir bestuur om spesifieke inligting oor organisasie-funksionering op 'n deurlopende basis aan werkers te versprei. Maatskaplike werkers kan gevoelens van kwesbaarheid ervaar indien hulle nie oor voldoende inligting van byvoorbeeld organisasiefunksionering beskik nie, wat weer dienslewering aan die verbruikersisteem belemmer. Individuele maatskaplike werkers behoort dus oor genoegsame inligting oor rol- en taakfunksionering in hulle spesifieke poste te beskik, ten einde hul moraal en produktiwiteit in die instansie te bevorder.

\section{INHOUD VAN KOMMUNIKASIE IN 'N WELSYNSINSTANSIE}

Dit is nodig dat die maatskaplike werkers kennis moet hê oor die inhoud van kommunikasie in 'n welsynsinstansie omdat dit hul werksfunksionering negatief kan beïnvloed indien hulle nie oor voldoende kennis daaroor beskik nie. Effektiewe kommunikasie, beide op 'n 
organisatoriese sowel as 'n persoonlike vlak, is sentraal tot sukses van kommunikasie in alle verhoudings, in hierdie geval die werkplek.

Die welsynsinstansie is in wisselwerking met 'n verskeidenheid van interne en eksterne sisteme. Hierdie wisselwerking en interafhanklikheid vereis die verspreiding van bepaalde inligting. Die maatskaplike werker in 'n instansie behoort oor spesifieke inligting oor die instansie te beskik as hy/sy effektief binne die organisasiestruktuur wil funksioneer. Die werker behoort volgens Botha (2000:16) kennis te hê oor die organisasiekultuur: die missie en visie van die instansie, doelstellings en doelwitte, nuwe programme, bronne en sterk en swak punte van die organisasie se interne aktiwiteite.

Cronjé (1986:119) maak die onderskeiding tussen algemene en spesifieke inligting waaroor 'n werker behoort te beskik. Die algemene inligting wat in 'n instansie aan personeel gekommunikeer te behoort word met die oog op effektiewe funksionering, kan in vier kategorieë verdeel word, naamlik inligting oor die organisasiekultuur, beplanningsaspekte, spesifieke situasies in die instansie asook inligting oor die sosio-ekonomiese sisteem en die takomgewing waarin die instansie funksioneer. Die aspekte word vervolgens hier uiteengesit:

- Inligting oor die organisasiekultuur, naamlik die interne funksionering daarvan, diensvoorstelle en/of programme, fasiliteite wat dit bied soos dagsorgfasiliteite, tehuise vir ouer persone, en inligting oor toekomsbeplanning (Cronjé, 1986:119).

- Inligting oor aspekte wat direk verband hou met beplanning in die instansie naamlik die missie, doelstellings, doelwitte, strategieë, beleide, reëls, prosedures en begroting (Weinbach, 2003:75).

- Inligting omtrent spesifieke situasies wat in die organisasiesisteem voorkom, byvoorbeeld veranderings in bestuur en personeel en die algemene kantooropset (Cronjé, 1986:119). Die werker behoort inligting hieroor te hê, byvoorbeeld as daar meer vrywilligers by projekte betrek kan word, sal dit ' $n$ invloed hê op beplanning van werksverrigting van 'n individuele werker omdat take in so 'n geval na die vrywilliger gedelegeer kan word.

- Inligting omtrent die sosio-ekonomiese sisteem en die taakomgewing waarbinne die instansie funksioneer, byvoorbeeld die aard van die verbruikersisteme (Cronjé, 1986:119). In die geval van 'n Vereniging van Liggaamlike Gestremdes sou die instansie slegs 'n diens lewer aan 'n spesifieke teikengroep, naamlik gestremde persone met 'n spesifieke fisiese gestremdheid. Ander inligting sou insluit: die voorkoms van maatskaplike behoeftes en probleme, byvoorbeeld armoede, werkloosheid, MIV/VIGS, kindermishandeling. Die maatskaplike werkers se kennis oor die probleme wat in 'n gemeenskap aanwesig is, sou die diensvoorstelle van 'n instansie rig. In die geval van 'n gemeenskap met 'n hoë werkloosheidsyfer kan dienste gerig word op werkskeppings- of vaardigheidsontwikkelingsprogramme. Die werker behoort ook kennis te hê oor beskikbaarheid van bronne en netwerke in ' $n$ gemeenskap en samewerking tussen hierdie rolspelers moet verkry word om aksies wat bydra tot doelbereiking te fasiliteer (De Giboja, 2001:40). Die bestaan van belangegroepe om na die behoeftes van die gemeenskap om te sien, is belangrik, sodat samewerking in gemeenskapsverband bewerkstellig kan word.

Teen die agtergrond van die voorafgaande word vervolgens aandag gegee aan spesifieke inligting waaroor 'n personeellid behoort te beskik wat noodsaaklik is vir die doeltreffende funksionering in hulle poste. Cronjé (1986:120) is van mening dat personeel beskik oor inligting oor hulle eie take, wat gewoonlik in posbeskrywings vervat word, want dit is nodig dat hulle bewus moet wees van hulle eie posisie in verhouding met die amptelike, formele 
gesagstruktuur in 'n welsynsinstansie. 'n Tweede aspek is hulle verhouding ten opsigte van informele organisering, naamlik individuele status, mag waaroor hulle beskik en aanvaarding deur kollegas. Ander aspekte sluit in: inligting wat hulle finansiële sekuriteit raak, naamlik salarisse en aanpassings daarvan en moontlikhede van bevordering in die instansie. ' $n$ Werknemer behoort te beskik oor inligting oor die aard en kwaliteit van sy werk en hiervoor moet 'n terugvoerkanaal binne die organisasiestruktuur geskep word. Die supervisiestelsel in 'n welsynsinstansie is die mees geskikte kanaal hiervoor. Die spesifieke inligting waaroor maatskaplike werkers behoort te beskik, is belangrik vir sy/haar eie individuele toekomstige beplanning in die welsynsinstansie en bereiking van persoonlike doelwitte.

Giffords en Dina (2003:75) beskou vertroue tussen bestuur en personeel by hierdie algemene inligting as noodsaaklik omdat dit tot konsensusbereiking lei, indien verskille tussen bestuur en werkers oor bepaalde aspekte sou ontstaan. Indien vertroue tussen bestuur en die maatskaplike werkers sou bestaan, sal dit die kommunikasie oor hierdie genoemde aspekte vergemaklik en tot beter werksverrigting van die individu kan bydra.

\section{KOMMUNIKASIESTRUKTURE}

Daar moet strukture in 'n welsynsinstansie geskep word om voorsiening te maak vir die voorafgaande tipes kommunikasie ten einde bepaalde inligting op 'n deurlopende basis aan personeel te kommunikeer. Vervolgens word vier strukture, naamlik supervisie, personeel en ander vergaderings, die komiteestelsel en bestuursinligtingstelsels in 'n welsynsinstansie bespreek.

\section{Supervisie}

Die term supervisie het verskillende definisies. Austin en Hopkins (2004:7) beskou die praktyk van supervisie soos volg: "Supervision practised as collaboration implies that supervisors and linestaff are working together toward some common aim." Hierdie samewerking impliseer dat daar na doelbereiking gestreef moet word. Samewerking vereis verder dat almal se deelname en perspektiewe as waardevol beskou word, en dat almal se sieninge gerespekteer word en dat konsensus oor besluite nagestreef word.

Kadushin en Harkness (2002:23) definieer die supervisor soos volg: “...an agency administrative-staff member to whom authority is delegated to direct, coordinate, enhance, and evaluate the on-the-job performance of the supervisee for whose work he or she is held accountable." Volgens die definisie is die supervisor in 'n instansie verantwoordelik vir die toewysing, koördinering, handhawing en evaluering van die werk van maatskaplike werkers. Die supervisor in 'n instansie is dus nie direk betrokke by dienslewering aan die verbruikersisteem nie, maar beïnvloed indirek dienslewering deur leiding aan maatskaplike werkers te gee. Skidmore (1995:246) sluit hierby aan en beskryf die funksies van supervisie as administratief, ondersteunend en opvoedkundig van aard. Die supervisor se hoofdoelstelling in ' $n$ instansie is dus om te verseker dat maatskaplike werkers 'n kwaliteitdiens aan die verbruikersisteem lewer in ooreenstemming met die welsynsinstansie se missie, doel, beleid en prosedures.

\section{Personeel en ander vergaderings}

Personeel-, komitee- en bestuursvergaderings in 'n welsynsinstansie is belangrike meganismes om inligting aan personeel te versprei. Brody (1993:106) beskryf sewe funksies van 'n vergadering, naamlik koördinering, verdeling van werk, spanbou, deurlopende verspreiding van inligting, probleemanalise, besluitneming en monitering. 
Samevattend kan 'n vergadering benut word om 'n probleem te bestudeer, om inligting in te samel, om aanbevelings te maak, om opvolgaksies op besluitneming te onderneem en om resultate te monitor. Vergaderings verseker dus dat voldoende inligting oor probleme ingesamel word en die regte besluite oor aksies geneem word.

\section{Komiteestelsel}

Skidmore (1995:130) is van mening dat elke formele instansie 'n komiteestelsel nodig het vir effektiewe en doeltreffende funksionering. Voorbeelde van komitees is hoëvlakkomitees, laevlakkomitees, tegniese komitees, taakgroepe, werkgroepe, programkomitees en adhockomitees. Die komitee bestaan uit professionele persone, en in ' $\mathrm{n}$ instansie is dit noodsaaklik dat alle personeel deurlopend by komitees as 'n vorm van personeelontwikkeling betrokke is. Die bestaan van komitees in 'n welsynsinstansie verseker dat die kommunikasieproses vlot verloop.

\section{Bestuursinligtingstelsels}

Bestuurders op alle vlakke van bestuur is betrokke by besluitneming. Bestuurders benodig akkurate, presiese, volledige en relevante inligting vir hul taakuitvoering. 'n Bestuursinligtingstelsel is 'n geskikte metode hiervoor. Kroon (1995:462) definieer 'n bestuursinligtingstelsel as 'n versameling van mense, prosedures en hulpbronne wat inligting insamel en prosesseer wat bestuurders betyds bereik om aksies te onderneem. Dit is strategiese inligting oor die instansie en is gewoonlik gerekenariseerd wat inligting toeganklik aan die bestuur en ook aan ander personeel in die welsynsinstansie maak.

\section{RESULTATE VAN DIE ONDERSOEK}

Die doel van die studie is om te bepaal watter tipe kommunikasiemediums en -hulpmiddels in 'n welsynsinstansie benut word en in watter mate dit effektief is om kommunikasie in organisasieverband tussen bestuur en maatskaplike werkers te bevorder. Skidmore (1995:206207) bespreek die belangrikste tipe kommunikasiemediums en -hulpmiddels, naamlik persoonlike onderhoude; vergaderings; briewe en memorandums; konferensies; amptelike verslae en sosiale aktiwiteite en vergelyk met Skidmore(1995) en ander toonaangewende internasionale en Suid-Afrikaanse outeurs se sienings, waarna aanbevelings gemaak word.

\section{Persoonlike onderhoude}

Dit is ' $n$ belangrike medium waar een-tot-een-kommunikasie verhoog word en individuele sake bespreek kan word. Die supervisiegesprek tussen die supervisor en die maatskaplike werker is 'n manier waarop persoonlike onderhoude kan plaasvind. Skidmore (1995:246) is van mening dat hierdie interaksie tussen supervisor en die individuele maatskaplike werker daarop gerig is om die bevoegdheid van laasgenoemde te verhoog. Kadushin (1992:19) bespreek die ekspressief-ondersteunende funksie van supervisie. Die supervisor het voorts die verantwoordelikheid om werkermoraal te bevorder, om werksverwante ontevredenheid te hanteer. Die doel hiervan is om werkers 'n gevoel van waarde as professionele persone, 'n gevoel van behoort en 'n sekuriteitsin in hulle werkverrigting te gee. Individuele supervisie verskaf 'n medium vir die voer van persoonlike onderhoude en bied dan 'n leergeleentheid wat persoonlike groei en ontwikkeling bevorder.

Die respondente is versoek om aan te dui hoe gereeld persoonlike onderhoude (supervisiegesprekke, konsultasiegesprekke en loopbaangesprekke) in die welsynsinstansie met hulle gevoer word. Die ondersoek het getoon dat persoonlike onderhoude 'n belangrike medium van kommunikasie is. Agt van die respondente $(n=10)$ het aangedui dat hulle een tot 
twee keer per maand persoonlike onderhoude voer, wat supervisie-, konsultasie- en loopbaangesprekke insluit. Een respondent het aangedui dat sy drie tot vier keer per maand persoonlike onderhoude voer, terwyl een respondent glad nie hierdie kommunikasiemedium benut nie. Volgens Skidmore (1995:247) verskaf die supervisiestelsel in die welsynsinstansie die medium vir die voer van persoonlike onderhoude. Die supervisor verskaf leiding aan werkers oor taakuitvoering in die welsynsinstansie en dus ook oor direkte dienslewering aan die kliëntsisteem. Uit die bevindinge blyk dit dat hierdie medium effektief deur maatskaplike werkers in die welsynsinstansie benut word.

Die respondente is versoek om aan te dui in watter mate die persoonlike onderhoude wat wel gevoer word, bydra tot hul persoonlike beplanning en -ontwikkeling, effektiewe dienslewering aan die verbruikersisteem of enige ander aspekte in hul pos.

\section{TABEL 1 \\ BYDRAE TOT PERSOONLIKE ONTWIKKELING VAN MAATSKAPLIKE WERKER}

\begin{tabular}{|l|c|}
\hline ONTWIKKELING & RESPONSE \\
\hline Persoonlike beplanning & 7 \\
\hline Persoonlike ontwikkeling & 8 \\
\hline Effektiewe dienslewering aan verbruikersisteem & 10 \\
\hline Ander & 3 \\
\hline Totaal & 28 \\
\hline
\end{tabular}

$\mathrm{n}=10$

Tabel 1 toon dat persoonlike onderhoude 'n direkte invloed op effektiewe dienslewering aan die verbruikersisteem het. Dit dra ook by tot persoonlike ontwikkeling en -beplanning van maatskaplike werkers. Ander response het getoon dat dit tot projekbeplanning en groepwerk bydra en begrip ten opsigte van die gemeenskap en sy funksionering verhoog. Een respondent het aangedui dat dit bydra tot beter verslagskrywing. Skidmore (1995:247) is van mening dat die supervisor die maatskaplike werkers in ' $n$ welsynsinstansie se werk fasiliteer sodat dit bydra tot effektiewe dienslewering aan die verbruikersisteem. Kadushin (1992:22) definieer supervisie as ' $n$ indirekte diens, dit impliseer dat die supervisor indirekte kontak het met die kliënt deur die maatskaplike werker. Die resultate van die ondersoek ondersteun die literatuur omdat dit aandui dat persoonlike onderhoude wel bydra tot die ontwikkeling van maatskaplike werkers en effektiewe dienslewering aan die verbruikersisteem bevorder.

\section{Personeelvergaderings}

Brody (1993:104) is van mening dat vergaderings nodig is in organisasieverband om belangrike sake te bespreek. Volgens Skidmore (1995:206) het personeelvergaderings twee hooffunksies, naamlik kommunikasie en besluitneming deur beide bestuur en personeel. Kommunikasie geskied mondelings binne vergaderings, maar word ook skriftelik opgevolg in die vorm van 'n notule. Botha (2000:35) sluit by Skidmore aan en is van mening dat hierdie notule die korrekte inligting aan lede moet gee en hulle met voorbereiding vir die volgende vergadering moet help.

Die volgende afdeling fokus op vergaderings en die drie aspekte wat die vraelys gedek het, was: die gereeldheid van die personeelvergaderings, tipe sake wat bespreek word en die belangrikste funksies van personeelvergaderings. 


\section{- Gereeldheid van personeelvergaderings}

Dit is noodsaaklik dat daar in organisasieverband gereelde vergaderings gehou moet word om inligting onder personeel te versprei. Die respondente moes aandui hoe gereeld vergaderings in hul kantoor plaasvind.

TABEL 2

GEREELDHEID VAN PERSONEELVERGADERINGS

\begin{tabular}{|l|c|}
\hline GEREELDHEID VAN VERGADERINGS & RESPONSE \\
\hline 1 keer per week & $0(0 \%)$ \\
\hline 1 keer per maand & $0(0 \%)$ \\
\hline Twee maandeliks & $1(10 \%)$ \\
\hline Drie maandeliks & $1(10 \%)$ \\
\hline Ander & $8(80 \%)$ \\
\hline Totaal & $10(100 \%)$ \\
\hline
\end{tabular}

$\mathrm{n}=10$

Volgens Tabel 2 het een respondent aangedui dat personeelvergaderings twee-maandeliks plaasvind en nog een respondent dat dit drie-maandeliks plaasvind. Die ander agt respondente se response het ingesluit: kwartaalliks, wanneer sake opduik, volgens behoefte, op aanvraag en wanneer nodig. Personeelvergaderings vind nie op 'n gereelde basis plaas nie, maar wel volgens die behoeftes van die maatskaplike werkers. Die bevindinge van die studie sluit aan by Brody (1993:106) se siening dat vergaderings in instansies nodig is om oor werksaangeleenthede te kommunikeer. Dit is duidelik dat hierdie medium in die welsynsinstansie hiervoor benut word.

\section{- Sake van bespreking}

'n Vergadering word deur Steenkamp en Bekker (1983:291) omskryf as 'n byeenkoms van twee of meer persone om aangeleenthede of sake van gemeenskaplike belang te bespreek en besluite daaroor te neem. Pearsall (2001) definieer 'n vergadering soos volg: "A team activity where a select group of people gathers to pursue a specific objective in an effort to solve or investigate a problem." Uit hierdie definisies is dit duidelik dat 'n vergadering slegs kan plaasvind as twee of meer persone teenwoordig is en daar vir ' $n$ spesifieke doel vergader moet word. In die welsynsinstansie is dit nodig dat spesifieke sake tydens 'n vergadering bespreek word om sodoende effektiewe dienslewering aan die verbruikersisteem te verseker.

Die aspekte wat hier onder sake van bespreking ingesluit was, is organisasiefunksionering; kantoorfunksionering, diensleweringspraktyke en beplanningsaspekte ten einde te bepaal wat as die belangrikste besprekingspunte beskou was.

Kantoorfunksionering is deur nege van die respondente as die belangrikste besprekingspunt tydens vergaderings beskou, terwyl organisasiefunksionering en diensleweringsaspekte beide deur sewe respondente as belangrik beskou is. Beplanningsaspekte word volgens vyf respondente minder tydens vergaderings bespreek. Brody (1993:106) beskou koördinering en verspreiding van werk in kantoorverband as van die belangrikste funksies van personeelvergaderings en die resultate van die studie stem hiermee ooreen. 


\section{- Funksies van personeelvergaderings}

Brody (1993:104) is van mening dat vergaderings in organisasieverband nodig is om belangrike sake te bespreek. Volgens Skidmore (1995:206) het personeelvergaderings twee hooffunksies, naamlik kommunikasie en besluitneming deur beide bestuur en personeel. Kommunikasie geskied mondelings binne vergaderings, maar word ook skriftelik in die vorm van 'n notule opgevolg.

Die respondente is versoek om aan te dui wat hulle as die belangrikste funksie(s) van personeelvergaderings beskou.

TABEL 3

FUNKSIES VAN PERSONEELVERGADERINGS

\begin{tabular}{|l|c|}
\hline FUNKSIES VAN PERSONEELVERGADERINGS & RESPONSE \\
\hline Kommunikasie & 3 \\
\hline Besluitneming & 1 \\
\hline Beide & 7 \\
\hline Ander & 3 \\
\hline Totaal & 14 \\
\hline
\end{tabular}

$\mathrm{n}=10$

Die meerderheid van die respondente (sewe), beskou beide kommunikasie en besluitneming as belangrike funksies van personeelvergaderings, soos blyk uit Tabel 3. Ander response ten opsigte van funksies het ingesluit: doelgerigtheid ten opsigte van projekte en werkverrigting en betrokkenheid; inligting en om bestuur betrokke te kry by projekbeplanning, hantering van dwingende probleme en uitdagings. Die resultate van die studie stem ooreen met die siening van Skidmore (1995:206) wat kommunikasie en besluitneming deur bestuur en werkers as een van die belangrikste funksies van personeelvergaderings beskou. Doelgerigte kommunikasie oor organisasiefunksionering tydens personeelvergaderings in die welsynsinstansie is noodsaaklik. Notules wat die werksaamhede van 'n vergadering dokumenteer, word vervolgens as nog 'n kommunikasiemedium bespreek.

\section{Notules van 'n vergadering}

Die notule dien as 'n rekord van die gebeure en werksaamhede van vergaderings. Volgens Skidmore (1995:206) is die notule 'n belangrike kommunikasiemedium in ' $n$ instansie omdat dit ' $n$ presiese weergawe van die besprekingspunte van ' $n$ vergadering is en lede van die vergadering help om spesifieke inligting te kry, asook om hulle vir daaropvolgende vergaderings voor te berei. Die Centre for Higher Education Transformation (2003:27) sluit hierby aan en noem dat notules van 'n verslag verskil omdat dit nie 'n verbatim rekord van debatte tydens die vergadering is nie, maar wel van besluite wat geneem is.

\section{Briewe en memorandums}

Briewe en memorandums kan vir die oordrag van ' $n$ informele of formele boodskap benut word. Sheafor, Horejsi en Horejsi (2000:178) is van mening dat in 'n welsynsinstansie standaardbriewe vir spesifieke situasies benut behoort te word. Inligting wat per brief oorgedra word, moet duidelik en akkuraat weergegee word sodat waninterpretering van die boodskap beperk kan word. Memorandums kan benut word wanneer spesifieke inligting vinnig oorgedra moet word. 
Die respondente moes aandui hoe briewe en memorandums as ' $n$ kommunikasiemedium in hul organisasie benut word.

Die response word in vier kategorieë gegroepeer, naamlik kommunikasie vanaf hoofkantoor, interne en eksterne kommunikasie en ander.

\section{TABEL 4}

BENUTTING VAN BRIEWE EN MEMORANDUMS

\section{KOMMUNIKASIE VANAF HOOFKANTOOR}

- Word vanaf hoofkantoor en bestuur na personeel (laer af in organogram) gestuur.

- Personeel kommunikeer ook via briewe aan hoofkantoor.

- Word vanaf hoofkantoor of streeksverteenwoordiger na kantoorhoof of direk na maatskaplike werker gestuur, gereelde kommunikasie vind op hierdie wyse plaas.

- Omsendbriewe vanaf hoofkantoor, met betrekking tot vakkundige aspekte en besluite.

\section{INTERNE KOMMUNIKASIE}

- Opdragte word daarop aangebring asook inligting; keerdatums word daarop aangebring indien terugvoering verlang word.

- Dit word so gou moontlik aan almal beskikbaar gestel, belangrike punte word uitgelig en opdragte word gegee en terugvoerdatums word ook gegee.

- Word gereeld gesirkuleer, moet teken, kry ook afskrifte.

- Inligtingstukke en kennisgewings word gesirkuleer vir kennisname en terugvoer, indien nodig, bv. inskakeling by opleidingsgeleenthede en weergee van inligting soos statistiek.

\section{EKSTERNE KOMMUNIKASIE}

- Kommunikasie met die supervisiesisteem vind veral deur middel van briewe en memorandums plaas aangesien die supervisor in Worcester gesetel is.

- Briewe en memorandums word by bestuursvergaderings bespreek en hanteer, korrespondensie (intern en ekstern) word deur middel van briewe hanteer.

- Om inligting aan verskeie persone oor te dra.

\section{ANDER}

- Memorandums word nie juis gebruik nie, verkry kennisgewings van takbestuur.

Die bogenoemde resultate stem ooreen met dié van Skidmore (1995:206) en Botha (2000:36) en Sheafor et al. (2000:178) wat van mening is dat briewe en memorandums benut word om 'n verskeidenheid van inligting (formeel en informeel) aan werkers te kommunikeer. In hierdie welsynsinstansie sluit dit kommunikasie vanaf die hoofkantoor na verskillende kantore in, sowel as interne kommunikasie in kantoorverband en ook eksterne kommunikasie met ander sisteme buite 'n spesifieke kantoor.

\section{Formele en informele konferensies}

Volgens Skidmore (1995:207) ontwikkel 'n bestuurder wat op 'n gereelde basis met personeel kommunikeer, 'n positiewe verhouding met hulle. 'n Amptelike konferensie, waar deskundiges genooi word om oor 'n spesifieke onderwerp referate te lewer, is 'n voorbeeld van formele 
konferensies. Die geselekteerde onderwerp vir 'n konferensie hou verband met 'n aspek of veld wat die kennis van werkers of van die wyer publiek kan uitbrei, wat dan tot direkte kommunikasie tussen personeel en die bestuurder lei. Die tipe konferensies bied 'n geleentheid vir werkers om hul idees, opinies en vrae aan die bestuurder oor te dra.

Dinkgroepe en personeelsamesprekings in die instansie is voorbeelde van informele konferensies. Dit lei tot direkte kommunikasie tussen personeel en die bestuurder en bied 'n geleentheid vir werkers om hul idees, opinies en vrae aan die bestuurder oor te dra. Dit is 'n effektiewe hulpmiddel in 'n welsynsinstansie omdat dit individuele bydraes van alle maatskaplike werkers verg ten einde doelbereiking moontlik te maak.

Uit die ondersoek is bepaal dat personeelsamesprekings (10 response) gereeld plaasvind, asook werk- en taakgroepe (drie response) wat daarop dui dat personeel op 'n gereelde basis met mekaar kan kommunikeer. Amptelike konferensies (vier response) word gereeld gehou, maar dinkgroepe (een respons) word nie gehou nie. Die bevindinge sluit aan by Skidmore (1995:206) se siening dat die benutting van die hulpmiddel as noodsaaklik beskou word omdat dit tot positiewe verhoudings tussen bestuur en personeel in ' $n$ welsynsinstansie kan lei en 'n goeie kommunikasiesisteem tussen personeel bevorder. Botha (2000:36) beweer dat hierdie tipe kommunikasiehulpmiddel net tot voordeel van die organisasie kan wees as resultate van die vermeerderde kennis en inligting in die voortgesette werksaamhede van die welsynsinstansie gereflekteer word.

\section{Amptelike verslae}

Amptelike verslae sluit in jaarverslae, begrotingsverslae, navorsingsverslae, finansiële state en statistiese opnames van die instansie. Die beginsel van deursigtigheid en verantwoordbaarheid van dienslewering aan die gemeenskap is hier ter sake, want hierdie tipe verslae sou vir die publiek antwoorde op bepaalde vrae oor instansie- funksionering kon gee.

Die respondente moes aandui tot watter verslae hulle in die instansie toegang het.

Die response word in Tabel 5 weergegee.

TABEL 5

TOEGANG TOT AMPTELIKE VERSLAE

\begin{tabular}{|l|c|c|}
\hline AMPTELIKE VERSLAE & JA & NEE \\
\hline Jaarverslae & 10 & 0 \\
\hline Begrotingsverslae & 8 & 2 \\
\hline Navorsingsverslae & 5 & 5 \\
\hline Totaal & 23 & 7 \\
\hline
\end{tabular}

$\mathrm{n}=10$

Uit Tabel 5 blyk dit dat werkers toegang het tot amptelike verslae van die instansie, tien van die respondente het toegang tot jaarverslae, agt tot begrotingsverslae en vyf $(n=10)$ het toegang tot navorsingsverslae. Dit impliseer dat werkers goed ingelig is oor die funksionering van die welsynsinstansie in die geheel en hulle kan hierdie inligting in hul eie diensleweringspraktyke benut. 


\section{Sosiale aktiwiteite}

Sosiale aktiwiteite soos middagetes, spanbou- en ander ontspanningsaktiwiteite skep die basis vir informele kommunikasie tussen personeel (Skidmore, 1995:207). Die tipe kommunikasie is noodsaaklik in ' $n$ welsynsinstansie, omdat dit belangrik is dat personeel op ' $n$ informele basis kan kommunikeer. Ook bou dit die moreel en motivering van maatskaplike werkers.

Die respondente het aangedui aan watter sosiale aktiwiteite hulle in die instansie deelneem.

TABEL 6

DEELNAME AAN SOSIALE AKTIWITEITE

\begin{tabular}{|l|c|c|}
\hline SOSIALE AKTIWITEITE & JA & NEE \\
\hline Tee & 8 & 2 \\
\hline Middagetes & 4 & 2 \\
\hline Spanbouaktiwiteite & 6 & 2 \\
\hline Ander & 4 & 0 \\
\hline Totaal & 22 & 6 \\
\hline
\end{tabular}

$\mathrm{n}=10$

Soos blyk uit Tabel 6 sluit sosiale aktiwiteite of waar werkers informeel met mekaar kan kommunikeer, teetye, middagetes en spanbouaktiwiteite in. Ander response sluit in: groepsupervisie-geleenthede wat soms as spanbousessies benut word; teetye en middagetes word benut om te sosialiseer en informeel te kommunikeer. Dagbeplanning vind soggens oor ' $n$ koppie tee plaas. Die afleiding word gemaak dat werkers wel op 'n gereelde basis informeel met mekaar kommunikeer.

Botha (2000:36) onderskryf die belangrikheid van sosiale aktiwiteite soos onthale,teetye, etes en personeelfunksies waar kommunikasie tussen personeel bevorder word en wat tot die moreel en motivering van alle personeellede bydra. Skidmore (1995:207) ondersteun die belangrikheid van werkers se betrokkenheid by sosiale aktiwiteite in 'n welsynsinstansie omdat dit 'n belangrike medium van informele kommunikasie tussen personeel is.

\section{Nuusbriewe}

Die gebruik van nuusbriewe in 'n welsynsinstansie is effektief om inligting oor spesiale nuusgebeure weer te gee en om die wyer publiek oor die funksionering van die organisasie in te lig. Sommige instansies gee kwartaallikse of jaarlikse nuusbriewe uit, wat inligting oor die instansie se ontwikkeling, spesiale dienste en nuwe projekte en programme insluit. Op 'n informele, skriftelike vlak is nuusbriewe 'n effektiewe manier om algemene inligting oor organisasie-ontwikkeling en interne gebeure aan die breë verbruikersisteem en publiek oor te dra (Botha, 2000:37).

\section{Kennisgewingsborde}

Formele en informele inligting kan hiervoor gebruik word. Memorandums, nuusbriewe en belangrike kennisgewings word op die bord aangebring om inligting aan personeel oor te dra. Volgens Botha (2000:37) help kennisgewingsborde om die effektiwiteit van genoemde kommnuikasiemediums te verhoog. 


\section{Telefoonoproepe}

Dit is ' $n$ tyd- en kostebesparende hulpmiddel wat benut word as inligting vinnig versprei moet word. Dit is meer effektief as byvoorbeeld 'n nota of ' $n$ memorandum, as daar byvoorbeeld erkenning vir 'n personeellid se prestasie gegee wil word, omdat dit persoonlike kontak insluit. Botha (2000:35) konstateer dat daar egter vir elke telefoonoproep deeglike voorbereiding gedoen moet word om te verseker dat korrekte inigting in die kortste moontlike tyd oorgedra word en reg verstaan moet word.

\section{Elektroniese kommunikasie: Die e-posstelsel}

Verskillende skrywers soos Hellriegel, Slocum en Woodman (1998); Kreitner en Kinicki (2001) en McShane en Von Glinow (2000) som die gebruik en voordele van die e-posstelsel op. Enkele voordele van die e-posstelsel is dat boodskappe vinnig geskep, geredigeer en gestoor kan word. Spesifieke inligting kan aan 'n verskeidenheid persone gelyktydig gestuur word. Dit is ook voordelig omdat inligting waaroor besluite later geneem kan word vooraf aan ontvangers gestuur word. Dit is 'n tyd- en kostebesparende hulpmiddel omdat inligting vinniger versprei word.

Die tipes kommunikasiehulpmiddels in die instansie wat respondente $(n=10)$ benut om inligting oor te dra is hoofsaaklik nuusbriewe (9), kennisgewingsborde (9) en telefoonoproepe (9), asook 'n e-posstelsel (5).

Die respondente moes hul antwoorde motiveer en die response (Tabel 7) sluit in:

\section{TABEL 7}

BENUTTING VAN ANDER VORME VAN KOMMUNIKASIE

\section{TELEFOONOPROEPE}

Telefoniese gesprekke word gevoer om opdragte uit te voer.

Telefoon is die belangrikste manier van kommunikeer.

Basiese inligting oor dienslewering word meestal telefonies oorgedra.

\section{NUUSBRIEWE EN KENNISGEWINGS}

Gereelde nuusbriewe word ontvang met keerdatums vir terugvoering.

Daar is "nie-amptelike" kennisgewings wat nuus oordra, nuusbriewe fokus op verwagtinge, veranderinge en opdragte met belangrike keerdatums. Almal het toegang tot die briewe.

Inligting oor funksies en programme wat aangebied word, word deur plakkate en inligtingsbronne oorgedra.

\section{E-POSSTELSEL}

Baie personeel het hul eie e-posadres, nuuswaardige inligting word deur die kantoorhoof versamel vir nuusbriewe.

Die kantoor beskik nie oor e-posfasiliteite nie. Ons beskik wel oor 'n faksfasiliteit wat kommunikasie ook vergemaklik.

E-pos is beskikbaar, maar word nie algemeen gebruik nie, slegs in die administratiewe afdeling.

Uit Tabel 7 is dit duidelik dat ander vorme van kommunikasie, naamlik nuusbriewe, kennisgewingborde en telefoonoproepe wel in die welsynsinstansie benut word. Met hierdie 
studie is bevind dat hierdie mediums van kommunikasie benut word vir formele sowel as informele kommunikasie in die welsynsinstansie. Dit word deur skrywers soos Skidmore (1995) en Botha (2000) ondersteun.

Riemtelegramme en die grondwet van die instansie, reglemente en handleidings word vervolgens as die laaste twee tipes van kommunikasiehulpmiddels in 'n welsynsinstansie bespreek.

\section{Riemtelegramme}

Inligting word op ' $n$ informele basis oorgedra en word nie deur bestuur gesanksioneer nie. Die vorm van verspreiding van inligting kan negatief of positief wees. Die sogenaamde "grapevine" kan skadelik wees as gerugte of skinderstories in ' $n$ instansie versprei word, en positief in die sin dat menings en idees tussen kollegas oorgedra word.

Die effek van die riemtelegram in 'n organisasie behoort nie volgens Botha (2000:36) deur bestuur onderskat te word nie, omdat dit ' $n$ sterk beïnvloedingsfaktor in die organisasie is. Bestuurders kan doelbewus inligting aan 'n spesifieke personeellid oordra met die doel dat inligting vinnig versprei word, byvoorbeeld wanneer 'n vergadering gekanselleer word en die riemtelegram benut word om die spesifieke inligting vinniger te versprei.

\section{Grondwet, reglemente en handleidings}

Botha (2000:36) noem dat geen organisasie kan bestaan of effektief funksioneer sonder hierdie kommunikasiehulpmiddels nie. Die tipe media is voorbeelde van formele skriftelike kommunikasie en is effektief omdat die riglyne wat in 'n konstitusie van 'n instansie vervat is, wetlik afdwingbaar is. Dit is verder doeltreffend omdat dit 'n medium is waarsonder kommunikasie in ' $n$ welsynsinstansie onmoontlik is, omdat dit riglyne vir dienslewering verskaf.

Volgens Cronjé (1986:129) sal die doeltreffendheid van al die genoemde kommunikasiehulpmiddels en -media vanweë struikelblokke beperk bly as maatskaplike werkbestuurders nie “...poog om die vloei en effek van kommunikasie te verbeter deur die aanwending van bepaalde tegnieke soos herhaling, verbetering van personeel se vermoë om te luister, die skep van kanale vir terugvoer, en die benutting van konsultante" op te skerp nie. Dit impliseer dat al die kommunikasiehulpmiddels en -media dus doeltreffend binne 'n welsynsinstansie benut en aangewend kan word om kommunikasie tussen personeel op al die vlakke van die instansie te verbeter.

\section{BESPREKING VAN RESULTATE VAN DIE STUDIE}

Die supervisiestelsel in 'n welsynsinstansie verskaf ' $n$ medium vir die voer van persoonlike onderhoude. Direkte leiding deur die supervisor aan die maatskaplike werker dra by tot effektiewe dienslewering aan die verbruikersisteem en bevorder die persoonlike en sosiale ontwikkeling van individue, gesinne en gemeenskappe wat die hoofdoel van welsynsprogramme van 'n welsynsinstansie is.

Twee hooffunksies van vergaderings in 'n welsynsinstansie is dié van kommunikasie en besluitneming deur bestuur en personeel wat tot die effektiwiteit van die kommunikasieproses in 'n welsynsinstansie bydra.

Briewe en memorandums is belangrike mediums van kommunikasie in die welsynsinstansie omdat dit inligting vinniger aan personeel versprei. Dit word ook benut om inligting vanaf die 
Hoofkantoor aan maatskaplike werkers oor te dra, asook om interne en eksterne kommunikasie in kantoorverband te bevorder.

Maatskaplike werkers in die welsynsinstansie het toegang tot amptelike verslae, naamlik jaar-, begrotings- en navorsingsverslae wat hul kennis oor organisasiefunksionering verhoog en bydra tot effektiewe dienslewering aan die verbruikersisteem.

Die maatskaplike werkers neem deel aan verskeie sosiale aktiwiteite in die welsynsinstansie. Sosiale aktiwiteite is 'n vorm van informele kommunikasie in die welsynsinstansie wat bydra om die moreel en motivering van werkers te verhoog.

Ander vorme van kommunikasie, naamlik telefoonoproepe, nuusbriewe, kennisgewingsborde en die e-posstelsel word deur die maatskaplike werkers in die welsynsinstansie benut vir informele en formele kommunikasie om inligting te versprei.

\section{Na aanleiding van die bevindinge van die studie word die volgende aanbevelings gemaak:}

- Supervisie is die medium waarbinne persoonlike onderhoude geskied en moet benut word as 'n terugvoerkanaal oor die werksaamhede van 'n individuele maatskaplike werker. Persoonlike onderhoude behoort op 'n gereelde basis met maatskaplike werkers in 'n welsynsinstansie gevoer te word om effektiewe dienslewering aan die verbruikersisteem te bevorder.

- Vergaderings behoort op 'n deurlopende basis in die welsynsinstansie plaas te vind omdat dit kommunikasie tussen personeel verhoog en tot beter besluitneming bydra.

- Die voortsetting en benutting van briewe en memorandums word aanbeveel omdat dit inligting vinniger aan personeel versprei.

- Amptelike verslae, byvoorbeeld jaarverslae, begrotingsverslae en navorsingsverslae moet aan alle maatskaplike werkers in die instansie beskikbaar wees omdat beskikbaarheid en toegang tot die verslae bydra tot beplanning en organisering van dienste van die welsynsinstansie. Botha (2000:36) is van mening dat elke maatskaplike werker onderrig moet word om hierdie tipe kommunikasiemiddele korrek te lees, te verstaan, hierop te reageer en hiervolgens te werk ten einde betekenis aan hul werk te verskaf.

- Maatskaplike werkers behoort aangemoedig te word om wel sosiale aktiwiteite in die welsynsinstansie by te woon omdat dit hul moreel en motivering verhoog. Dit dra ook by tot verhoogde produktiwiteit en lei gevolglik tot effektiewe dienslewering aan die verbruikersisteem.

- Voortgesette benutting van telefoonoproepe, nuusbriewe, kennisgewingsborde en die eposstelsel word aanbeveel omdat dit kommunikasie in die welsynsinstansie verhoog en inligting vinniger aan personeel versprei.

- Kommunikasie tussen die bestuur en personeel oor missie, doel, beleid, prosedures en werkswyses in 'n welsynsinstansie is belangrik om effektiewe dienslewering aan die verbruikersisteem te bevorder. Dit verhoog produktiwiteit en motivering by maatskaplike werkers indien hulle oor spesifieke inligting van die organisasiesisteem beskik. Die benutting van verskillende kommunikasiemediums en -hulpmiddels verhoog kommunikasie in die welsynsinstansie tussen die bestuur en personeel, sowel as tussen personeel onderling omdat dit verskillende wyses bied waarop inligting tussen personeel versprei en oorgedra word. 


\section{BIBLIOGRAFIE}

AUSTIN, D.M. 2002. Human services management: organizational leadership in social work practice. New York: Columbia University Press.

AUSTIN, M.J. \& HOPKINS, K.M. 2004. Supervision as collaboration in the human services: building a learning culture. California: Sage Publications Inc.

BABBIE, E. \& MOUTON, J. 2001. The practice of social research. Oxford: Oxford University Press.

BOTHA, N.J. 2000. Supervisie en konsultasie in maatskaplike werk. Bloemfomtein: Druforma.

BRODY, R. 1993. Effectively managing human service organizations. London: Sage Publications.

CENTRE FOR HIGHER EDUCATION TRANSFORMATION. 2003. University and Techinikon councils: a guide to meeting procedures. Pretoria.

COOPER ALTMAN, J. 2003. A qualitative examination of client participation in agencyinitiated services. Families in Society: The Journal of Contemporary Human Services, 84(4):471-479.

CRONJÉ, J.I. 1986. Administrasie as basiese komponent in die funksionering van die vrywillige welsynsorganisasie. Stellenbosch: Universiteit van Stellenbosch. (D.Phil Proefskrif)

DE GIBOJA, M.G. 2001. An exploratory study of administrative practice in collaboratives. Administration in Social Work, 25(2):39-59.

DE VOS, A.S., STRYDOM, H., FOUCHÉ, C.B. \& DELPORT, C.S.L. 2005. Research at grass roots - for the social sciences and human service professions $\left(3^{\text {rd }} \mathrm{ed}\right)$. Pretoria: Van Schaik Publishers.

GIFFORDS, E.D. \& DINA, R.P. 2003. Changing organizational cultures: the challenge in forging successful mergers. Administration in Social Work, 27(1):69-81.

HELLRIEGEL, D., SLOCUM, J.W. (jr) \& WOODMAN, R.W. 1998. Organizational behavior $\left(8^{\text {th }}\right.$ ed $)$. Cincinnati: South-Western.

KADUSHIN, A. 1992. Supervision in social work $\left(3^{\text {rd }}\right.$ ed $)$. New York: Columbia University Press.

KADUSHIN, A. \& HARKNESS, D. 2002. Supervision in social work $\left(4^{\text {th }}\right.$ ed). New York: Columbia University Press.

KELLY, D. 2000. Using vision to improve organisational communication. Leadership and Organisation Development Journal, 21(2):92-101.

KREITNER, R. \& KINICKI, A. 2000. Organizational behavior $\left(5^{\text {th }}\right.$ ed). Boston: McGrawHill Irwin.

KROON, J. (ed) 1995. Algemene bestuur ( $2^{\text {de }}$ uitg). Pretoria: Kagiso Tersiêr.

LEWIS, J.A., LEWIS, M.D., PACKARD, T. \& SOUFLEE, F. (jr) 2001. Management of human service programs $\left(3^{\text {rd }}\right.$ ed $)$. Belmont: Brooks/Cole. 
430

McSHANE, S.L. \& VON GLINOW, M. 2000. Organizational behavior. Boston: McGrawHill Irwin.

NEUMAN, K. 2003. Developing a comprehensive outcomes management program: a ten step process. Administration in Social Work, 27(1):5-21.

PACKARD, T. 2001. Enhancing staff commitment through organizational values: the case of a homeless shelter. Administration in Social Work, 25(3):35-52.

PEARSALL, J. (ed) 2001. Consice Oxford Dictionary. Oxford: Oxford University Press.

SCHULTZ, H. (ed) 2003. Organisational behaviour: a contemporary South African perspective. Pretoria: Van Schaik Publishers.

SHEAFOR, B.W., HORESJI, C.R. \& HORESJI, G.A. 2000. Techniques and guidelines for social work practice $\left(5^{\text {th }} \mathrm{ed}\right)$. London: Allyn \& Bacon.

SKIDMORE, R.A. 1995. Social administration: dynamic managent and human relationships $\left(3^{\text {rd }}\right.$ ed). London: Allyn and Bacon.

SMIT, P.J. \& CRONJÉ, G.J. 2002. Management principles: a contemporary edition for Africa $\left(2^{\text {nd }}\right.$ ed). Kenwyn: Juta \& Co.

STEENKAMP, S.M. \& BEKKER, M.A. 1983. Kantooradministrasie 1. Johannesburg: McGraw-Hill Boekmaatskappy.

TUBBS, S.L. \& MOSS, S. 1994. Human communication $\left(7^{\text {th }}\right.$ ed). New York: McGraw-Hill.

WEINBACH, R.W. 2003. The social worker as manager: a practical guide to success $\left(4^{\text {th }}\right.$ ed). Boston: Allyn and Bacon.

WERNER, A. 2003. Organisational culture and ethics and diversity in a global environment. In: SCHULTZ, H. (ed) Organisational behaviour: a contemporary South African perspective. Pretoria: Van Schaik Publishers.

Me Raelene Arendse, junior dosent, Departement Maatskaplike Werk, Universiteit van Stellenbosch, Stellenbosch, Suid-Afrika. 